\title{
El efecto mariposa en la educación para la paz
}

\author{
The Butterfly Effect on Peace Education
}

\author{
Evelyn Cerdas Agüero' \\ Instituto de Estudios Latinoamericanos \\ Universidad Nacional \\ Heredia, Costa Rica \\ evelyncer@yahoo.com
}

Recibido 07 de febrero de 2012 • Corregido 28 de abril de 2012 • Aceptado 28 de junio de 2012

Resumen. El presente trabajo aborda el tema de la educación para la paz. El objetivo es generar, utilizando como metáfora el efecto mariposa, una reflexión acerca de la importancia de la educación para la paz en el proceso de cambio del ser humano y de la sociedad. Se plantea la educación para la paz como un derecho humano, una vivencia y un proceso de aprendizaje que se lleva a la práctica protagonizado por el ser humano. Busca la transformación de actitudes y acciones para fundar relaciones armoniosas basadas en el respeto y reconocimiento de los derechos humanos, la libertad y la dignidad de cada persona.

Palabras claves. Educación para la paz, educación, paz, efecto mariposa, derecho humano.

Abstract. The objective of this paper on peace education is to generate a reflection, through the metaphor of the butterfly effect, on the importance of educating for peace during the change process of human beings and society. It proposes education for peace as a human right, an experience and learning process that is put into practice by human beings. It aims at changing attitudes and actions to create harmonious relationships based on the respect and recognition of human rights, and the freedom and dignity of every person.

Keywords. Education for peace, education, peace, butterfly effect, human right.

\section{Introducción}

En diversas culturas han existido diferentes concepciones acerca de la paz, sin embargo, en la historia de la humanidad siempre ha estado presente la búsqueda constante de la paz vista como una aspiración del ser humano. La historia bélica, lamentablemente, en muchas ocasiones, ha guiado esta búsqueda para transformar esa realidad, la cual relata una necesidad de paz en el marco de una concepción restringida (paz como ausencia de guerra) ante la necesidad del cese de injusticias y violencia.

\footnotetext{
Máster en Derechos Humanos y Educación para la Paz de la Universidad Nacional, Costa Rica. Bachiller en Relaciones Internacionales de la Universidad Nacional, Costa Rica. Coordinadora del Proyecto Aula Activa Juegos Cooperativos para la Educación para la Paz en el IDELA, Universidad Nacional. Directora de la Revista Latinoamericana de Derechos Humanos del IDELA, Universidad Nacional. Es docente del curso Espacios Lúdicos para la Educación en Derechos Humanos. Ha sido docente en la Maestría en Derechos Humanos y Educación para la Paz y la Licenciatura en Estudios Latinoamericanos del IDELA en la Universidad Nacional.
} 
La educación para la paz no se limita a este tipo de paz. Más bien la visualiza como armonía interna del ser humano, en las relaciones humanas y con la naturaleza; así mismo como un valor humano, principio ético y derecho humano; como manifestación de la cooperación, la solidaridad, el amor y la comunicación efectiva, y como la resolución alternativa de conflictos, entre otros.

Es una educación que busca que la paz se convierta en una práctica cotidiana dirigida al cambio; por lo tanto, el presente trabajo tiene como objetivo generar una reflexión acerca de la importancia de la educación para la paz en el proceso de cambio del ser humano y de la sociedad, para lo cual utiliza la metáfora del efecto mariposa.

Lo anterior dirige el trabajo a reflexionar acerca de la importancia de la transformación de las personas, sus actitudes y sus acciones por medio de la educación para la paz, y cómo este cambio deviene de asumir responsabilidades, comprometerse con el cambio personal y poseer la capacidad de influenciar a otras personas, por medio del efecto mariposa, para lograr la práctica de la paz en la vida cotidiana.

El texto inicia con una visión acerca del concepto de educación para la paz, el cual está integrado por dos procesos que son al mismo tiempo derechos humanos, la paz y la educación. En dicho entramado se visualiza esta como un proceso de aprendizaje, integral y vivencial, necesario para la realización del ser humano y el respeto a su dignidad. Posteriormente, se analiza el efecto mariposa y la influencia que este genera en las personas y en la sociedad, y se compara con el efecto transformador necesario de la educación para la paz.

\section{La educación para la paz}

La educación para la paz no es fácil de definir, pues se constituye por dos términos: educar y paz, los cuales son más que dos conceptos, son procesos vivenciales que duran toda la vida; son intencionales y creadores de conciencia; implican responsabilidad, apropiación de conocimientos, y desarrollo de habilidades y actitudes para el ejercicio de diversos roles sociales en pro del desarrollo humano y de la calidad de vida con mejores oportunidades.

La educación es un proceso que no es neutral, tiene un sentido y una intencionalidad que dirige a analizar acerca de cuál es la realidad que se quiere construir, el futuro que se quiere forjar, así como la conciencia, actitudes y habilidades que se requieren en las personas para el logro de estas. Implica conocer las ideas, la historia, las ideologías, los pensamientos y los valores. Y más que esto, es la disposición que existe en las personas para construir, de forma conjunta, la sociedad y las realidades que en ella se entrelazan. Es también el compromiso y la responsabilidad ante el reto que esto conlleva, para que se haga conciencia de la necesidad de una sociedad democrática, participativa, y respetuosa de los derechos humanos, la dignidad humana y la paz.

La educación se define como: "(...) el hecho de que alguna persona procure ayudar a otra para que esta logre un desarrollo significativo de su personalidad a través de algún tipo de 
aprendizaje (...)". (Quintanilla, 1991, en Torres, 2007, p. 13) En este contexto vale la pena decir que nadie se educa solo/a, sino en comunidad con otra persona u personas. Esto es necesario tanto para el desarrollo de la personalidad humana, como para el crecimiento en la sociedad. Es, por lo tanto, un proceso interactivo y cooperativo en el cual las personas aprenden entre sí, crean, cuestionan, y son flexibles y sensibles a los cambios, necesidades humanas y sociales. El hecho de educarse en comunidad toma en consideración que toda persona conoce, tiene experiencias y proyectos, está en constante interacción con la realidad, es un sujeto cognoscente, participante y aprendiente en todo momento de su vida, en el ámbito formal, informal o no formal.

De tal forma que la educación es considerada como "(...) un proceso por el cual los seres humanos se van autoconstruyendo en comunicación con otros seres humanos (...)" (López, 2006, p. 9 en Gómez, 2010, p. 126). Este proceso de autoconstrucción se dirige a la transformación de actitudes y acciones que generan irrespeto a los derechos humanos, discriminación, no aceptación de las diferencias, falta de solidaridad, exclusión, desigualdad, violencia e indiferencia. Así como a la formación, consolidación de una conciencia crítica de la realidad y conocimiento de las causas de la falta de libertad, desigualdad, pobreza e irrespeto hacia la persona humana y su dignidad.

Al respecto es necesario que las personas puedan ver y analizar estas actitudes y acciones para trabajar en estas, lo cual es posible si se les dan las herramientas necesarias para fortalecer sus conocimientos, habilidades, destrezas y capacidades, y crear una conciencia para reestructurar actitudes en aquellas que promuevan el compromiso, la responsabilidad y el respeto en las relaciones humanas.

No se trata solo de transmitir información sino de desarrollar una conciencia crítica en la cual las personas tengan conciencia de su papel en la sociedad y la que quieren lograr. Se trata de poder reconocer qué es lo que existe en el interior, qué le define, con qué y con quiénes se identifica y cuáles son sus vivencias. Esta lucha solo se logra ganar en el momento en que cada persona asume su responsabilidad en la sociedad y en la construcción de una cultura de paz, en la cual se vivan los derechos humanos -cuestión que no se basa solo en el reconocimiento sino en su práctica-.

Es, también, un proceso solidario y cooperativo en el cual los intereses trascienden de lo individual a lo colectivo moviendo el corazón hacia otras personas y actuando para un encuentro con el trabajo conjunto y la coexistencia pacífica, referida a la vivencia e interiorización de nuevas actitudes y acciones dirigidas a la búsqueda de la calidad de vida sustentada en el reconocimiento y respeto de la dignidad del ser humano. Además, no es la simple suma de las partes de la sociedad o de voluntades, sino es el compromiso y la conciencia de seres humanos movidos hacia la posibilidad de convivir de forma solidaria, autorrealizarse, construir y compartir aprendizajes en comunidad.

La educación es fundamental para el desarrollo armonioso del ser humano y para sus relaciones, porque promueve la comprensión, el afecto y el respeto, elementos fundamentales para una cultura de paz y para el reconocimiento de los derechos humanos. Se basa en conocimientos y experiencias previas, la incidencia de estas en otras personas $y$, sobre todo, en el descubrimiento de la realidad que mueve a las personas a la búsqueda de su comprensión y propuestas creativas y reflexivas. Es decir, la 
URL: http://www.una.ac.cr/educare

educación tiene intencionalidad, la cual está marcada por la cultura, la política y las diversas razones de ser de una sociedad, por eso también es un poder que libera de la opresión, por tanto, no es neutral, tiene objetivos de transformación y construcción individual, colectiva y social, se dirige al logro de uno o varios fines como: el desarrollo del ser humano, reconocimiento y respeto de los derechos humanos, y la libertad; la comprensión entre los seres humanos, los pueblos y las naciones; el respeto a las diferencias, y la construcción y mantenimiento de la paz.

Estos fines son respaldados por la Declaración Universal de Derechos Humanos, la cual estipula la educación como un derecho humano. En su artículo 26 enuncia algunos de sus principios centrales:

2. La educación tendrá por objeto el pleno desarrollo de la personalidad humana y el fortalecimiento del respeto a los derechos humanos y a las libertades fundamentales; favorecerá la comprensión, la tolerancia y la amistad entre todas las naciones y todos los grupos étnicos o religiosos, y promoverá el desarrollo de las actividades de las Naciones Unidas para el mantenimiento de la paz. (Naciones Unidas, s. f., párr. 2)

Así como la educación, la paz también es un derecho humano y una vivencia que está implícita en un concepto amplio, complejo y multidimensional, vinculado con las relaciones y las condiciones, es decir: "(...) no puede existir paz positiva si hay relaciones caracterizadas por el dominio, la desigualdad y la no-reciprocidad, aunque no haya ningún conflicto abierto" (Lederach en Caireta y Barbeito, 2005, p. 19). Esta noción no se limita al concepto de paz como ausencia de guerra, sino que incluye el término griego eirene, el cual implica armonía, serenidad y tranquilidad interna del ser humano y social. Además, comprende la construcción y promoción de relaciones no violentas basadas en el respeto, la solidaridad, la confianza, la comunicación, el diálogo y el afecto.

La paz es un derecho humano consagrado en la Declaración Universal de Derechos Humanos: "Artículo 28. Toda persona tiene derecho a que se establezca un orden social e internacional en el que los derechos y libertades proclamados en esta Declaración se hagan plenamente efectivos" (Naciones Unidas, s. f., Artículo 28, párr. 1).

La base de este derecho es el reconocimiento de la dignidad del ser humano, el reconocimiento y respeto de sus derechos y libertades fundamentales. Es indispensable para la realización de otros derechos.

La paz se concibe en el espacio social, no es algo inalcanzable, sino que se manifiesta en el diario vivir y en nuestras relaciones; lo indicado sería que se haga notoria en medio de estas y por estas, por lo que se asume que la paz inicia en cada persona, en el grupo del que cada quien forma parte y con este, en el contexto comunitario y con él, y en el entorno y con este mismo. En la tabla siguiente se ilustra cómo se manifiestan estas relaciones: 
Tabla 1

Paz y relaciones humanas

\begin{tabular}{|c|c|c|c|}
\hline Conmigo mismo/a & En/con el grupo & En/con la comunidad & En/con la naturaleza \\
\hline $\begin{array}{l}\text { Forma en la cual me } \\
\text { relaciono conmigo mismo/a }\end{array}$ & Relación con mis pares & $\begin{array}{l}\text { Relación con mi } \\
\text { comunidad }\end{array}$ & $\begin{array}{l}\text { Mi relación con el } \\
\text { medio natural }\end{array}$ \\
\hline $\begin{array}{l}\text { Forma en la cual debería ser } \\
\text { esa relación }\end{array}$ & $\begin{array}{l}\text { ¿Cómo podrían ser estas } \\
\text { relaciones interpersonales? }\end{array}$ & $\begin{array}{l}\text { Interacción con mi } \\
\text { comunidad }\end{array}$ & $\begin{array}{l}\text { ¿Cómo podría mejorar } \\
\text { esta relación? }\end{array}$ \\
\hline $\begin{array}{l}\text { Áreas en las que debería } \\
\text { mejorar }\end{array}$ & $\begin{array}{l}\text { Áreas en las que debería } \\
\text { mejorar }\end{array}$ & $\begin{array}{l}\text { ¿Como deberían ser } \\
\text { esas relaciones? }\end{array}$ & Áreas débiles y fuertes \\
\hline Afirmación/autoestima & $\begin{array}{l}\text { Forma en la que me } \\
\text { comunico, escucho, } \\
\text { expreso lo que siento y } \\
\text { pienso }\end{array}$ & $\begin{array}{l}\text { Áreas en las que } \\
\text { debería mejorar }\end{array}$ & $\begin{array}{l}\text { Participación en } \\
\text { proyectos ambientales }\end{array}$ \\
\hline $\begin{array}{l}\text { ¿Reconozco, acepto y respeto } \\
\text { mis derechos y deberes? }\end{array}$ & Mi participación & $\begin{array}{l}\text { Participación } \\
\text { en soluciones y } \\
\text { propuestas }\end{array}$ & Actitudes y acciones \\
\hline Lo que me inspira y motiva & $\begin{array}{l}\text { Forma en que resuelvo } \\
\text { conflictos }\end{array}$ & Protagonismo & Visión integral \\
\hline Mi participación & Autonomía & Autonomía & $\begin{array}{l}\text { ¿Me siento parte de un } \\
\text { todo? }\end{array}$ \\
\hline Mis metas, sueños y deseos & $\begin{array}{l}\text { Interés y responsabilidad } \\
\text { por el bienestar y derechos } \\
\text { de las demás personas }\end{array}$ & $\begin{array}{l}\text { ¿Cómo es la } \\
\text { convivencia? }\end{array}$ & $\begin{array}{l}\text { Actitudes y acciones de } \\
\text { cooperación }\end{array}$ \\
\hline Mi autonomía & ¿Promuevo el diálogo? & $\begin{array}{l}\text { ¿Promuevo la } \\
\text { cooperación? }\end{array}$ & $\begin{array}{l}\text { ¿Promuevo la } \\
\text { conservación y el } \\
\text { manejo de recursos? }\end{array}$ \\
\hline Mi liderazgo & Convivencia & Participación & $\begin{array}{l}\text { Afecto hacia la } \\
\text { naturaleza }\end{array}$ \\
\hline Afecto, empatía & Cooperación & Papel educativo & $\begin{array}{l}\text { Respeto al derecho a un } \\
\text { medio ambiente sano }\end{array}$ \\
\hline $\begin{array}{l}\text { Sentido y propósito de mi } \\
\text { vida }\end{array}$ & & $\begin{array}{l}\text { Pertenencia a } \\
\text { organizaciones } \\
\text { comunales, } \\
\text { educativas, culturales, } \\
\text { religiosas }\end{array}$ & $\begin{array}{l}\text { Participación en } \\
\text { propuestas educativas } \\
\text { y de solución a } \\
\text { problemas ambientales } \\
\text { y sociales }\end{array}$ \\
\hline $\begin{array}{l}\text { Mi bienestar, felicidad y } \\
\text { armonía }\end{array}$ & & $\begin{array}{l}\text { Compromiso con mi } \\
\text { comunidad }\end{array}$ & \\
\hline
\end{tabular}

Nota: Elaboración propia basado en Caireta y Barbeiro, 2005, p. 21. 
URL: http://www.una.ac.cr/educare

Siguiendo esta unión de procesos, es imperativo comprender que la educación para la paz busca crear espacios para construir y practicar la cultura de paz en la cotidianeidad, esta debe interiorizarse individual y colectivamente; al mismo tiempo, plantea relaciones pacíficas y armoniosas, inicialmente con nosotros mismos, con otras personas y con la naturaleza. Implica buscar la paz como un valor que se debe vivir en la vida diaria, en los tiempos y espacios de las relaciones sociales. Asimismo, debe promover cambios de actitud que se reflejen en las acciones de la vida cotidiana. Esta cotidianeidad es el escenario formado por las interacciones entre los individuos en diferentes contextos: en el hogar, en el aula, al cruzar la calle, al ir al supermercado o al conducir.

Lo anterior sugiere que es un proceso de aprendizaje y práctica protagonizado por el ser humano en busca de su realización y desarrollo, un proceso vivencial que se refiere a cómo llevarla a la práctica en la realidad. Es uno de los caminos más eficaces para prevenir y transformar las actitudes de no aceptación de las diferencias, de no respeto mutuo, de insolidaridad, de discriminación, de ausencia de diálogo y para resolver conflictos de forma pacífica. Pero no solo es un instrumento, sino un fin en sí misma, porque es un proceso de transformación de actitudes y fortalecimiento de habilidades puesto que:

(...) Educar es enseñar el arte de llegar a ser humano y ese arte se aprende solamente en el contacto con otro ser humano que nos contagie a propósito, es decir, que tenga la intención sistemáticamente planificada, vivida y evaluada, de contagiar de humanidad a otros buscando, para ello, su complicidad, su libre compromiso para irse dejando contagiar. (López; 2006, p. 183 en Gómez, 2010, p. 126)

El arte de llegar a ser humano es el arte de educarse conjuntamente para la vida, la autonomía y la libertad, lo cual se logra con el compromiso, la dedicación, el deseo y de ir más allá en las relaciones humanas, en la búsqueda del beneficio común y no solo individual. De forma que las personas puedan mirar las diferencias y respetarlas para actuar juntos/as, aceptando que se tiene la capacidad de afectar y de ser afectados/as y mostrando una sensibilidad dirigida a relaciones en las cuales se acorte la distancia entre el decir y el hacer para el logro de la calidad de vida, libertad, afecto y reconocimiento de la dignidad sin exclusión.

El artículo 2 de la Declaración de Luarca (Asturias) sobre el derecho humano a la paz $(2008)^{2}$ se refiere al derecho a la educación para la paz y los derechos humanos de la siguiente forma:

Esta fue redactada por un comité de expertos en Asturias con el objetivo de que fuese considerada por la ONU. 
Toda persona tiene derecho a recibir una educación en la paz y los derechos humanos, fundamento de todo sistema educativo, que contribuya a generar procesos sociales basados en la confianza, la solidaridad y el respeto mutuo, facilite la solución pacífica de los conflictos y ayude a pensar de una forma nueva las relaciones humanas. (p. 112)

Pensar y vivir de una nueva forma las relaciones humanas implica una educación para la paz dirigida a "(...) aprender a vivir juntos y con los otros (para desarrollar la comprensión del otro y la percepción de las formas de interdependencia respetando los valores del pluralismo, comprensión mutua y paz) (...)" (Delors, 1996, p. 122 en Monclús y Sabán, 1999, p. 102). Para aprender a ser este ser humano, para su surgimiento, se deben desarrollar las capacidades personales, ejercer las libertades, ser autónomos, asumir responsabilidades y crecer en la solidaridad, la esperanza y el amor humano.

Brinda, también, una perspectiva positiva de la paz, se refiere a otra forma de verla más allá de lo opuesto a la guerra, sino como lo opuesto a la violencia, la cual tiene muchas manifestaciones visibles y poco visibles como la directa, estructural, simbólica, cultural y no solo la guerra. Pero, además, implica tomar acciones frente a esta y sus manifestaciones y a no quedarse en la pasividad. Implica vencer el temor de enfrentarse a la violencia; la no aceptación del irrespeto, la inseguridad, la violación de los derechos, la amenaza a la dignidad humana; y el no mantenerse inactivos/as ante la injusticia, sino luchar para la transformación.

Asume el planteamiento de una perspectiva creativa del conflicto; se refiere a los medios pacíficos, creativos e innovadores de resolverlos. Puesto que siempre existen, la idea es resolverlos de forma que se pueda aprender de ellos. Implica lograr que se dé un proceso de cooperación y de búsqueda de elementos en común entre las partes, entre las cuales exista el objetivo común de buscar soluciones de forma tal que todas las partes involucradas puedan ganar.

La educación para la paz se fundamenta en una serie de principios, los cuales se presentan en la siguiente tabla: 
URL: http://www.una.ac.cr/educare

Tabla 2

Principios de la educación para la paz

\begin{tabular}{ll}
\hline Es educación en valores. & - Se fundamenta en determinados valores y promueve su vivencia. \\
& $\begin{array}{l}\text { Conlleva valores como: justicia, cooperación, solidaridad, } \\
\text { compromiso, autonomía, respeto, amor, comprensión, aprecio. }\end{array}$ \\
& $\begin{array}{l}\text { Presenta críticamente determinados valores como: conformismo, } \\
\text { individualismo, intolerancia, etnocentrismo. }\end{array}$ \\
\hline $\begin{array}{l}\text { Es una educación desde la acción y } \\
\text { para la acción. }\end{array}$ & - Busca que las personas tengan conciencia de su potencial. \\
& - Busca acción en la realidad. \\
\hline $\begin{array}{l}\text { Es un proceso continuo y } \\
\text { permanente. }\end{array}$ & - Invita a reflexionar y mirar la realidad críticamente para incidir en ella. \\
\hline $\begin{array}{l}\text { Afecta todosajo y formación constante. } \\
\text { etapas educativas como eje } \\
\text { transversal del currículo. }\end{array}$ & - Es vincula con la responsabilidad, el compromiso y la dedicación. \\
& - Está presente en el currículo oculto. \\
\hline $\begin{array}{l}\text { Es educación para la crítica y la } \\
\text { responsabilidad. }\end{array}$ & - Piene un enfoque integrador e innovador. \\
\hline
\end{tabular}

Nota. Elaboración propia basada en Jares, 2004, p. 32 y Jares, 1999, p. 125.

Es una educación que crea procesos de aprendizaje para desaprender la violencia y vivenciar la paz en las relaciones humanas, pues la violencia, a través de la historia, ha causado la pérdida de millones de vidas humanas, la indignación, la pobreza, el hambre, la competencia salvaje, las guerras, la falta de oportunidades, la exclusión y la miseria. Es una educación centrada en valores en la que se prefiere y busca la cooperación en vez de la competencia, el amor en lugar del odio, la alegría ante la tristeza, la aceptación y respeto sobre la discriminación, y la solidaridad por encima de la competencia. Es, entonces, educar para una forma de vida que implique el cambio de actitudes y la reestructuración de aquellas estructuras mentales aprendidas, por lo tanto, es una educación que induce a: 
(...) trabajar en un horizonte que supere los propósitos verbales alejados de la acción. Dicho horizonte es el de la pedagogía de la cultura y de los derechos humanos y de la paz, cuyo objetivo es contrarrestar las múltiples exclusiones del otro -exclusión social, política, de la palabra y del afecto-. Solo si logramos desterrar la negación del otro, podremos construir un nuevo mapa de la convivencia. (Restrepo, 2011, p. 190)

Así, la educación para la paz implica:

- El respeto y ejercicio de los derechos humanos

- El diálogo

- La solidaridad

- La aceptación, aprecio y respeto a la diversidad en todos sus sentidos

- La paz como una forma de vida

- La comunicación asertiva

- La búsqueda y práctica de soluciones creativas y pacíficas para los conflictos

- La no violencia

- La acción social y política

- La búsqueda de la realización del ser humano, entre otros

Se trata de educar para construir, apropiarse, promover y vivir una cultura de paz, caracterizada por valores, actitudes, tradiciones, formas de conducta y de vida. Por tanto, se basa en el respeto a la vida, la promoción y las prácticas de la no violencia, por medio de la educación, el diálogo, la cooperación, la igualdad de derechos y de oportunidades, la libertad, la justicia, la aceptación de las diferencias y la solidaridad (Naciones Unidas, 1999). Este proceso reconoce que el ser humano es protagonista de su propia historia, sujeto y actor del cambio, constructor de la paz, que basa su modo de vida en el respeto de los derechos humanos y en la dignidad humana. Centrar la educación en la persona humana es creer que tiene un potencial y reconocer que posee las capacidades que le permiten participar de forma autónoma, decidida y activa en el desarrollo individual, colectivo e incidir en la sociedad.

De esta manera, se busca que la educación para la paz sea uno de los instrumentos y fines que contribuyen para que las personas sean constructoras de la cultura de paz y desarrollen potencialidades para crear cambios donde los derechos humanos sean una realidad y la vivencia de la paz una práctica en la cotidianeidad; cambios que se pueden generar por medio de un efecto mariposa. 
URL: http://www.una.ac.cr/educare

\section{El efecto mariposa en la educación para la paz}

El efecto mariposa se refiere a un postulado de la teoría del caos, el cual plantea que el simple aleteo de las alas de una mariposa sería suficiente para generar un huracán. Su nombre proviene de un antiguo proverbio chino: "el poder de las alas de una mariposa se puede percibir en el otro lado del mundo" (Briggs y Peat, 1999, p. 43). De ahí que el científico Edward Lorenz Lorenz (2001, p. 181) planteó el efecto mariposa por medio de la siguiente pregunta: "¿El aleteo de las alas de una mariposa en Brasil puede causar un tornado en Texas?". Este efecto implica que una mínima alteración en las condiciones iniciales puede generar grandes efectos en otro lugar o a miles de kilómetros. Este concepto se aplicó a las variaciones climáticas, al analizar que pequeñas alteraciones pueden incrementar 0 disminuir la frecuencia de fenómenos climáticos como los tornados. Aunque no se esté hablando de condiciones climáticas ni de condiciones iniciales, sino de sociedades y seres humanos que evolucionan, creo que en la educación para la paz los pequeños cambios que haga una persona (al menos) pueden generar grandes efectos aún en medio de un panorama caótico y seres humanos impredecibles, quienes, por sus diferencias, no se llegan a conocer completamente.

El efecto mariposa motiva a pensar que si únicamente un movimiento de las alas de una mariposa es capaz de producir un tornado, entonces es posible que los previos y siguientes movimientos también puedan causar efectos; de igual forma, es probable que los aleteos de otras mariposas también tengan otros efectos o causen los mismos. Así que si las alas de una mariposa pueden causar un tornado, existe la probabilidad de que también lo pueda evitar, de tal forma que las acciones y actitudes del ser humano pueden causar efectos tan negativos como los que causaría un tornado o evitarlos. Por el contrario, podría generar y multiplicar, también, efectos positivos.

Este efecto se enuncia en los estudios realizados por Lorenz (2001), en los cuales plantea que un sistema no lineal se caracteriza por situaciones en las que influencias muy sutiles pueden generar una transformación de todo el sistema; entonces, en sistemas como lo sociales, pequeños efectos generan cambios pequeños que al ser acumulativos o trascendentales pueden modificarlos. Lo anterior se debe a que en los sistemas (caóticos) todo está conectado mediante retroalimentación positiva o negativa (Briggs y Peat, 1999). Esta interconexión sustenta la importancia de la educación para la paz en los cambios sociales a través de las personas, quienes por medio de influencias individuales pueden generar grandes tornados que pueden cambiar la historia, porque las personas siempre cuentan con alguien próximo en quien pueden ejercer una influencia (sutil), incluso solo con las palabras, donde se utiliza la comunicación como un motor que mueve la sociedad desde el plano individual e incluye diversas voluntades que lo convierten en colectivo.

Es necesario reconocer que la realidad es un sistema caótico en diversos panoramas como el político, social y económico. 
Un ejemplo de caos muy cotidiano y complejo lo constituye la alta velocidad en las calles. Esta situación genera accidentes de tránsito (caos vial), de forma tal que muchas personas quedan con problemas físicos muy serios o hasta fallecen. Una familia que se ve afectada por la muerte de uno de sus miembros puede obtener efectos negativos en muchas áreas (caos familiar). Si el caso es que esta persona era quien proveía para satisfacer las necesidades básicas de la familia como vivienda, vestido y alimentación, estas ya no serán cubiertas, lo cual produce un impacto en los derechos de las personas, especialmente si son niños y niñas, en lo que respecta a su desarrollo, acceso a la alimentación, vivienda, vestido, educación (caos en los derechos humanos).

El caos se ha generado por diversas circunstancias, tales como la falta de conciencia acerca de los efectos de conducir a altas velocidades o en estado de ebriedad, la falta de educación vial o de su calidad, el irrespeto a la vida humana y la ausencia de solidaridad, entre otros. Lo contrario sucede si este caos se empieza a combatir desde la infancia, inculcando el respeto a la vida, la solidaridad, las consecuencias de los actos sobre las vidas de otras personas, el respeto a las leyes, etc. La incidencia positiva en una persona afectaría de forma positiva en su vida y en los derechos de los miembros de una familia y les evitaría situaciones como las mencionadas.

Este ejemplo provee una noción de que el caos está presente en la sociedad, en la violencia en las calles, la violencia intrafamiliar, los homicidios, la explotación infantil, la discriminación, la ausencia de buena alimentación y provoca una interconexión que deviene en una serie de consecuencias negativas, pero que también pueden estar sujetas a transformación y causar el efecto opuesto.

Así, esta interconexión del sistema (sociedad) explica que en el efecto mariposa algún aleteo genera un efecto positivo que cambia el sistema social caótico, aunque no necesariamente inmediatamente, debido a la impredecibilidad, pero sí por medio de la influencia sutil. Esta influencia es la opción que cada persona tiene para incidir en otras o en diversas circunstancias, para bien o para mal, y que utilizada de forma positiva e intencional puede provocar grandes o pequeños cambios que, de alguna forma, transforman vidas y hasta la sociedad.

La influencia sutil está ligada con la libertad y autonomía del ser humano para ejercerla, así como el compromiso hacia la humanidad y consigo mismo/a, de manera que "(...) aunque no poseamos el poder controlador en un sentido tradicional, todos poseemos el «el efecto mariposa» de la influencia sutil" (Briggs y Peat, 1999, p. 51). Esto es desafiar el poder tradicional, el status quo, la dominación opresiva, las diversas manifestaciones de la violencia, iniciando con cambios personales que impacten de forma positiva y transformadora a quienes están alrededor, sin violencia sino con la propuesta de la educación para la paz: noviolencia ${ }^{3}$, transformación positiva y creativa del conflicto, solidaridad, cooperación, comprensión, diálogo, afecto, alteridad, respeto, reconocimiento, garantía y práctica de los derechos humanos.

3 Se utiliza el noviolencia en una sola palabra para denotar que no se refiere únicamente a la ausencia de violencia (no violencia) sino a la no pasividad ante la injusticia, a la toma de acciones y a la desobediencia ante el poder opresor. 
URL: http://www.una.ac.cr/educare

Posiblemente la influencia sutil no sea inmediata, pero puede causar un efecto mariposa de gran magnitud. Por ejemplo, los actos de Gandhi, la Madre Teresa, Rosa Parks, Martin Luter King reflejan que el poder de la influencia sutil radica en enfrentarse a la opresión con el compromiso y deseo de mejorar y liberarse; acto que al inicio podría parecer sencillo, pero que puede generar consecuencias que revolucionen la historia. Aunque puede ser que no se logren los objetivos, se sienta un precedente que motiva a otras personas a luchar y reconocer sus derechos y libertades, lo cual puede generar un efecto impredecible y podría ser fundamental para cambiar el sistema.

El efecto mariposa considerado en la educación para la paz se enfoca en la influencia que pueden tener las personas y la capacidad para ejercerla en la sociedad, parte de contextos más inmediatos para lograr cimentar una cultura de paz en la que se respete la dignidad humana. Dicha influencia parte del reconocimiento individual de las propias actitudes, capacidades, de la autonomía y la libertad. Constituye una función primordial en la educación para la paz, en el sentido de que la persona pueda:

- Reconocerse como ser humano sujeto de derechos y responsabilidades.

- Autoafirmarse como una persona con dignidad.

- Reconocer y desarrollar sus habilidades para la comunicación diálogo, manejo y resolución de conflictos; así como propuestas creativas para diversas situaciones.

- Adquirir conocimientos, desarrollar actitudes y habilidades para luchar contra la violencia.

- Ser sensible ante las necesidades humanas.

- Respetar, reconocer, comprender y aceptar a otras personas.

- Poseer un pensamiento crítico y autónomo acerca de la realidad y las injusticias sociales.

- Poner en práctica la luchar por la justicia, la solidaridad, la cooperación.

- Vivenciar la paz y ser parte de la construcción de una cultura de paz.

El reto está en no dejarse vencer por las circunstancias ni por el sentimiento de impotencia cuando no se presentan los efectos esperados y no dejar de luchar. En tal caso, las personas seríamos parte de quienes se resisten al cambio y contribuyen a perpetuar la violencia y las injusticias.

Esto me recuerda a un cuento que leí hace un tiempo de autor desconocido. El cuento hacía referencia a un elefante cautivo desde que estaba pequeño, lo habían atado con una cadena a una estaca, el elefante luchó por soltarse y por romper la cadena, pero aunque haló 
mucho no lo logró porque era más fuerte que él. Al tiempo, ya muy cansado, se dio por vencido y no lo volvió a intentar. Con el pasar de los años el animal creció, se hizo grande y fuerte, las personas que lo observaban se preguntaban cómo era que un animal de tal tamaño y con tanta fuerza no podía liberarse de la cadena tan pequeña y la estaca tan débil. Pero el elefante ya nunca lo había intentado más, no miró el cambió que había tenido con los años, sus capacidades ni las oportunidades, porque su mente estaba programada de tal forma que estaba conforme y oprimido con su realidad.

Estas actitudes que llevan a continuar en la cautividad y a resistirse al cambio son llamados ciclos límites (Briggs y Peats, 1990), porque permiten que se perpetúen los modelos de conducta impuestos, muchas veces generalizados, inhiben el cambio porque generan impotencia. Muchos de estos ciclos límites radican en la impotencia causada por la injusticia social, la discriminación, la desigualdad, la violencia, la falta de oportunidades, la violación de derechos; situaciones que oprimen al ser humano y condicionan su vida.

Lograr ejercer la influencia sutil para causar un efecto mariposa libertador requiere un esfuerzo, pero además actitudes de esperanza, reconocimiento de la realidad, de las capacidades, habilidades, creencias y necesidades para asumir retos y responsabilidades para tener el deseo, convicción y compromiso de liberarse.

Ante este panorama, es necesario analizar algunos elementos del efecto mariposa que podemos considerar:

No es solo causa-efecto: Aunque el punto central del efecto mariposa radica en el planteamiento de que pequeñas causas iniciales generan grandes efectos, es necesario aclarar que en la educación para la paz no solo se trata de causa y efecto, donde B causa C o D (en una relación unidireccional) y no integral o multidireccional. Por el contrario, existe un vínculo por medio del cual se da un proceso de acciones, reacciones e impacto en las personas, relaciones y situaciones, ya que al estar hablando de personas no se trata de reacciones químicas de causa y efecto, sino procesos y relaciones humanas que impactan a quienes están involucrados y a quienes forman parte del contexto en el cual existen diferencias de género, culturales, de ideología, de oportunidades, entre otras.

Sin embargo, más que una relación causa y efecto se plantea una relación de interdependencia o sistémica, en la cual la humanidad es un sistema donde converge una serie de factores integrantes y todo se relaciona e influye; por lo tanto, siempre hay acciones que afectan, pero no a todos/as por igual, gracias a la heterogeneidad del ser humano; estaríamos hablando, entonces, de vínculos causales. El ser humano está llamado a tomar conciencia de que sus acciones y actitudes afectan de forma positiva o negativa $y$, en el momento que asuma la responsabilidad que esto implica, puede intentar que estos efectos sean positivos. 
URL: http://www.una.ac.cr/educare

$\checkmark$ La proporcionalidad de causa-efecto:

En la educación para la paz, la esperanza se mueve en el sentido de que pequeñas causas, rupturas, incidencias (aleteos) puedan generar pequeños efectos o cambios individuales que implican una multiplicidad de cambios (efecto en cadena) que generan un impacto mayor a nivel colectivo. Por ejemplo, desde el plano individual, la práctica de la comunicación asertiva en situaciones de conflicto puede generar que este no continúe en escalada y se le dé un mejor manejo o solución.

Por otro lado, como el sistema social y los seres humanos son impredecibles, la norma no es estricta: "(...) pequeñas causas producen pequeños efectos, y grandes causas grandes efectos (...) Una causa pequeña produce un gran efecto (...). Una causa grande produce un pequeño efecto (...)" (Cazau, 1995, párr. 5).

Esto, debido a que una pequeña causa puede generar un gran efecto $y$, por ende, grandes cambios. Por ejemplo, un pequeño cambio de actitud del/la docente en la forma de tratar al estudiantado puede motivar a este grupo a cambiar actitudes hacia su forma de ver la vida, metas y estudios e incentivarlo a terminar su educación formal hasta graduarse, lo cual se reflejará en mejores posibilidades laborales, de salud, vivienda y calidad de vida.

El punto central con respecto a la proporcionalidad causa-efecto es tener la visión lo suficientemente amplia para ver los pequeños cambios como significativos, lo cual también requiere esperanza. En la educación para la paz es indispensable tener una visión positiva que se transmita a las personas, a pesar de las situaciones, así como para buscar mejorarlas, de lo contrario se genera un cansancio y aceptación de la realidad que puede llevar hacia la pasividad e inactividad ante esta.

$\checkmark$ Imprevisibilidad: No se puede pronosticar con certeza el efecto o la magnitud de los cambios al educar para la paz, puesto que es un proceso que dura toda la vida y el sistema social tiene la característica de ser dinámico y con contextos sociales, culturales, económicos y políticos diferentes, así como las personas también lo son. No obstante, se plantea la educación para la paz como procesos de cambio y efectos que siempre son reales. La educación se centra en los otros y las otras, en su descubrimiento progresivo, en la convivencia armoniosa, en su reconocimiento, respeto y aprecio: En este sentido, la educación busca enfocarse en el reconocimiento y aceptación de las diferencias que enriquecen la humanidad y fortalecen la autonomía del ser humano.

$\checkmark$ El ser humano no está aislado: Las situaciones sociales no son aisladas, puesto que el ser humano vive y se desarrolla en comunidad. Cada persona es parte de un contexto, una cultura, de un sistema social y de un entramado de interacciones que le ayudan en su desarrollo. Esto permite multiplicar los efectos de la educación para la paz en las interacciones humanas y su incidencia en otras personas por medio de actitudes y acciones, al generar un efecto aún en otras generaciones.

$\checkmark$ Trascender de lo individual a lo colectivo: una variación puede generar cambios al otro lado del planeta, implica que los cambios se dan desde el plano individual 
para trascender a la colectividad. Se concibe al ser humano como parte de un todo o colectividad humana, no como partes aisladas, sino integrales en una humanidad. En el momento en que la persona asume "ser" parte integral de esta, se apropia de su humanidad individual que implica un compromiso consigo y con la colectividad.

$\checkmark$ Permite procesos de retroalimentación: no son lineales, sino vinculantes (algunos autores hablan de vínculos circulares), al ser la educación para la paz un proceso, el cual permite ver y analizar causas, efectos, fortalezas, debilidades y nuevas propuestas. Ejemplo: el análisis de un determinado conflicto con respecto a las técnicas utilizadas o no para la comunicación asertiva permite aprender de los errores e innovar, puesto que las experiencias del ser humano le permiten volver al origen de determinadas situaciones para mejorar, lo cual se convierte en una oportunidad para el aprendizaje y no en un fracaso.

Estos elementos permiten reflexionar que el efecto mariposa inicia en la esperanza del cambio y de comprometerse con este, desde el ámbito individual en el cual cada persona se pueda dar cuenta que no es una isla, sino que convive con otras, por lo que la esperanza y el afecto lo/a mueve a reconocer a los/as otros/as para trascender a lo colectivo y pensar en construir en comunidad para el logro de la paz.

\section{La metamorfosis de la mariposa: su representación para el ser humano}

Las mariposas tienen diversas etapas de desarrollo que podríamos comparar con la evolución interior del ser humano en un proceso de trasformación: de una oruga que podría no ser muy hermosa para algunas personas surge una mariposa lista para iniciar un viaje. Es significativo puntualizar en la importancia de la metamorfosis de la mariposa, proceso biológico por el cual se desarrolla una mariposa. La palabra metamorfosis deriva del griego $\mu \varepsilon т а \mu o ́ \rho \varphi \omega \sigma ı \varsigma$ y significa "transformación". Las mariposas tienen una metamorfosis completa, es decir, un proceso de transformación total, lo cual implica que pasan por varias fases en su desarrollo, entonces: ¿Qué representa la metamorfosis para el ser humanos en la educación para la paz? La respuesta la intento dar a continuación con una metáfora:

$\checkmark$ Huevo: Después de varios días los huevecillos de la mariposa se hacen transparentes, de manera que se pueden ver las larvas.

Existen etapas en la vida en las que parece que el ser humano está en una cáscara para protegerse y desarrollarse. En la educación para la paz es importante que el proceso sea para introspección y conocimiento, soñar, pensar en sus actitudes, percepciones, verse así mismo y autoconocerse. Es necesario que la persona tenga un proceso de autoconocimiento, de afirmación y se empodere de su realidad y sus objetivos, de forma tal que se pregunte: ¿cuál es mi propósito en la vida? 
URL: http://www.una.ac.cr/educare

$\checkmark$ Oruga: en esta etapa la oruga se alimenta constantemente y muda en promedio cinco veces en un período de tres semanas.

Asimismo, el ser humano tiene la capacidad de cambiar positivamente hacia un "horizonte de esperanza". A partir de la etapa anterior se autonoce y se afirma, puede mirar qué es lo que debe cambiar, sus opiniones, esperanzas, creencias, actitudes, decisiones, acciones y conductas; lo cual le permite un crecimiento.

En este período las orugas no tienen ojos compuestos, lo cual implica que no tienen una buena visión, no es amplia. En la educación para la paz, es necesario que el ser humano amplíe su visión con respecto a la realidad y a su visión del mundo, y con respecto a los cambios necesarios que debe realizar para su desarrollo y el de los demás, con una visión con esperanza. Entonces se pregunte: ¿cuál es mi visión?

Tampoco poseen patas, lo que permite recordar que la paz es una utopía que le permite al ser humano continuar caminando hacia su logro, para lo cual es necesaria esa aceptación para iniciar el camino hacia la construcción de la paz. Carecen de alas, las cuales les permitirían levantar su vuelo, estas representan las oportunidades que tiene la persona humana hacia nuevas realidades y relaciones sociales, las cuales muchas veces no tiene, no busca, no las desea o no tiene conciencia de ello. En esta etapa la persona puede reconocer lo que tiene y lo que no tiene, las posibilidades, habilidades, destrezas; las oportunidades, sueños y deseos.

Crisálida (capullo o pupa): La oruga se envuelve en un capullo hecho por ella misma, en el cual sufre cambios profundos.

Es el proceso de transformación, este le permitirá batir las alas muy pronto (y generar el efecto mariposa). Es la etapa en la que como seres humanos maduramos y conocemos nuestras realidades, una vez que nos miremos en la crisálida, la cual es nuestro interior. Nos permite mirar quiénes somos, cómo vivimos, cómo nos relacionamos, cómo son nuestras actitudes, qué es lo que queremos lograr, cuál es nuestro papel en la sociedad, cuál es nuestra meta, y qué podemos aportar. Lo cierto es que hay quienes nunca salen de la crisálida, pues han preferido el conformismo, el no hacer nada, la resignación, la pena, el status quo, el lamento o la simple indiferencia.

En esta fase la oruga se mueve de manera que desplaza la piel vieja, en poco tiempo la crisálida se torna más traslucida, se resquebraja y sale la mariposa para hacer sus primeros movimientos con sus alas. Aunque se halle totalmente libre, las alas de la mariposa están plegadas a su cuerpo, pero con la ayuda del sol y sus movimientos estimulan la irrigación de las alas y logra la expansión total para iniciar su vuelo. Esos pequeños movimientos para batir sus alas son aquellos cambios de actitud que le van permitiendo al ser humano ser libre para batir sus alas. Esto requiere un esfuerzo individual, un compromiso consigo mismo pero también social. Representa una lucha por su autonomía. 
$\checkmark$ Adulto: Es la etapa en la cual la mariposa tiene su desarrollo completo, las mariposas adultas inician su ciclo de reproducción, para luego volar hasta cumplir su ciclo de vida. Sale la mariposa de su crisálida, ya transformada, lista para batir sus alas en la sociedad y producir cambios, y generar el "efecto mariposa". Representa el ciclo productivo del ser humano. En la educación para la paz es importante que las personas pensemos en cuál es nuestro propósito, cuál es el efecto que queremos dejar en las vidas de las demás personas y en la sociedad.

¿Qué representa cada aleteo de la mariposa? Representa un acto: una manifestación de respeto hacia uno mismo, hacia el medio ambiente y hacia los demás; una actitud, la forma de comunicarnos, el diálogo, la solidaridad, la cooperación, el aprecio y aceptación de las diferencias, el afecto, la búsqueda de nuevas alternativas, el amor, la lucha por la justicia. Representa la actitud diferente que incide en el cambio, cada aleteo es individual, pero su magnitud o fuerza, velocidad y secuencia generan una unidad de aleteos que se suman y tienen más fuerza para generar el tornado.

El aleteo de la mariposa es movimiento, para algunos percibido como inestabilidad, la cual es la que causa inconformidad con lo que parece normal (manifestaciones de la violencia, injusticia, desigualdad); esto crea un "desorden" en el orden establecido en la cotidianeidad y surge como manifestación de la normalidad. Sin embargo, este aleteo crea nuevas dinámicas y modifica las ya existentes.

\section{Ejes fundamentales del efecto mariposa en la educación para la paz}

El efecto mariposa en la educación para la paz se fundamenta en el principio de la acción. Esto implica que se da en las vivencias de la persona humana y debe haber una brecha muy estrecha, o en el mejor de los casos ninguna, entre:

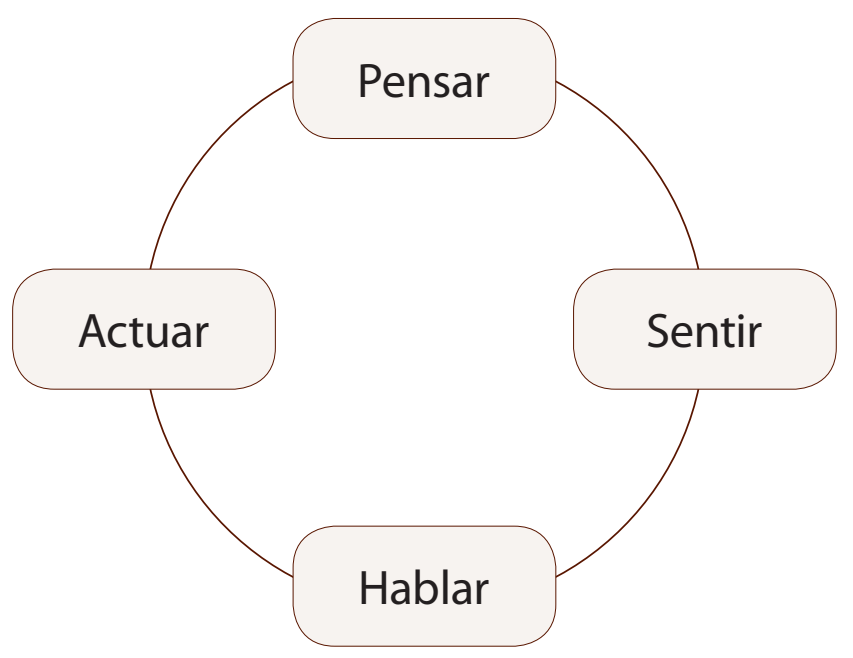

Figura 1. Elaboración propia. 
URL: http://www.una.ac.cr/educare

Esta acción se manifiesta en la esencia del ser humano, guiada por dos principios: ser paz y hacer paz.

$\checkmark$ Serpaz:

Ser consciente de que lo que yo soy causa un efecto, yo causo "algo" en otras personas: aprecio, respeto, tristeza, afecto, seguridad, confianza, temor, odio. Esto es generado por el impacto de mis actitudes, acciones, omisiones y relaciones. El efecto de la mariposa se puede comparar con la parábola que menciona Jesús en la Biblia, donde una lámpara si está encendida debe alumbrar, puesto que no está hecha para ponerse debajo de una cama; de igual manera la mariposa está hecha para volar y no para quedarse en su crisálida, para lo cual debe intentar mover sus alas y provocar la irrigación y su movimiento. Ese intento inicial genera el principio del vuelo, es decir, si no se realiza el intento con un propósito, las alas no inician.

No se trata con la Real Academia Española (RAE) (2001), el término "ser" indica "ser capaz o servir" también implica "esencia o naturaleza" o "modo de existir". "Ser" pertenece al dominio de uno mismo. Ser paz es sentir la paz interior para reflejarla, hablarla y actuarla; es inspirar, mover, incidir, impactar, tener una razón de existir que trasciende el yo y el solo hecho de vivir. Esto presupone trabajar consigo mismo, primero, pues ciertamente la paz inicia en el interior del ser humano, llámese alma, mente o corazón.

Ser paz es quien soy en mi humanidad y espiritualidad, en mi integralidad como persona; es mi conducta, mis conocimientos, mis sentimientos y mis pensamientos. Un "ser" en su humanidad que tiene un propósito y que no es neutral en su existencia.

Ante tales significados, el ser humano -individualmente y después como parte de una colectividad- puede preguntarse: ¿Cuál es mi esencia, cuál es mi naturaleza y cuál debería ser? ¿Cuál ha sido, es y puede ser mi modo de existir? Y, entonces, caben las preguntas: ¿Para qué existo? ¿Para qué soy? ¿Para ser paz?

\section{$\checkmark$ Hacer paz:}

Es la manifestación de nuestros pensamientos, las actitudes y las acciones que reflejan estas actitudes. La palabra "hacer", según la RAE (2001), se refiere a "(...) producir algo, darle el primer ser, (...) ejecutar, poner por obra una acción (...)". Es decir, la acción por medio de la cual el ser humano causa los cambios para transformar, el accionar del aprender a vivir juntos, de cooperar, de ser solidarios, de dialogar, es su práctica efectiva. Pues la acción nace en el pensamiento, en el conocimiento, en el sentir. Es, por lo tanto, una decisión hacerlo realidad. Esta acción emana de la humanidad misma del ser, construye, inspira, afecta y transforma, se ejemplifica en la práctica, en la realidad, en la existencia de una coherencia entre pensar-sentir-hablar-accionar. 


\section{Conclusión}

La educación para la paz es considerada un proceso de autoconstrucción en el cual se debe tener claridad acerca de la sociedad que se tiene y cuál es la que se desea lograr, porque es necesario que exista una conciencia de que lo que las personas son es lo que construyen, por tanto, se requiere un proceso de autoconstrucción personal, con respecto a las actitudes, aprendizajes, habilidades, creencias e idolologías que se tienen. Mirar hacia el interior humano busca crear una conciencia de responsabilidad individual para con las demás personas y para sí mismas, para reestructurar actitudes y fortalecer aquellas que dignifican al ser humano, respetan sus derechos y buscan su desarrollo pleno y autónomo. Así, la educación para la paz no se centra en transmitir conocimientos sino en impactar al ser humano en su complejidad, en todo su ser integral, su forma de vida, su visión de mundo y sus perspectivas de la realidad.

Es una transformación interna que trasciende de lo individual a lo colectivo para un encuentro y reconocimiento de las personas que están alrededor y para la coexistencia pacífica con estas; pero además, para afectarlas de forma positiva para vivir y construir la paz de forma solidaria, cooperativa y afectiva.

La educación para la paz, también, se centra en formar una conciencia de reconocimiento de que la paz no está dada, se construye, respeta, reconoce, hay que luchar por ella, no es estática, sino un proceso evolutivo, un derecho que hay que defender, un valor que hay que vivir, y por sí sola no genera ningún cambio sino están los actores y actrices que tomen la responsabilidad de generar acciones para el cambio y su construcción constante. La paz no es un ente abstracto, no es solo una aspiración de la mente humana o del corazón, la paz debe ser proyectada, ser vivencial, ser acción y reacción ante la realidad injusta y violenta.

Es, además, educar para ser paz y hacer paz, para tener esperanza, sueños de una mejor experiencia y convivencia humana, una visión que aspira y apuesta por la vida y no por la muerte; es el pensamiento más íntimo y lleno de afecto y solidaridad para con los otros/as y se refleja en la praxis cotidiana. Asimismo, es una dimensión del desarrollo humano, de la vida misma y del crecimiento armonioso en la sociedad. Comprende una educación para el crecimiento personal y social, con el fin de "aprender a vivir juntos/ as", o sea, una educación para la transformación, no solo para evitar conflictos armados y sus consecuencias, sino para luchar contra la violencia y para la realización plena del ser humano.

Es importante reconocer que la educación para la paz se centra en lograr la vivencia, la práctica de la paz, una conciencia crítica en las personas, una nueva visión de la realidad; lograr que asuman e interioricen el compromiso y la responsabilidad para transformar y construir, de forma conjunta, una sociedad mas justa, libre, respetuosa de los derechos humanos y de la dignidad humana; principios fundamentales para vivir en paz. Promueve la paz por medio de las relaciones humanas, iniciando con cada persona, el grupo más 
URL: http://www.una.ac.cr/educare

inmediato, la comunidad y con la naturaleza; educar para construir una cultura de paz en la cual todos/as desarrollen sus potencialidades y asuman compromisos para ser parte activa del proceso.

Lo anterior hace pensar que el ser humano posee la capacidad de actuar en la sociedad, modificar la realidad individual y las individuales de la colectividad para incidir en esta como un conjunto; se manifiesta por medio del amor, la cooperación, el respeto, la bondad, la solidaridad, la comunicación y mueve el proceso de transformación desde el individuo hasta la colectividad. Es una esperanza que motiva a creer que las personas tienen potenciales para lograr que surjan pequeños cambios que pueden afectar a los seres humanos, de forma importante y positiva, para lograr grandes transformaciones, por medio del efecto mariposa en la educación para la paz.

Lo positivo del efecto mariposa se centra en el hecho de constituir una metáfora que mueve a reconocer que cada persona es parte integral de un todo. Las decisiones que tome y las acciones que lleve a cabo van a producir un efecto en su vida y en la de otras personas. Además, implica reflexionar en el aspecto de que lo que se hace y se dice en el presente, refleja, en gran manera, el futuro, tanto en los aspectos positivos como en los negativos; por ende, es necesario partir de que en la educación para la paz es necesario mirar el presente y reflexionar acerca de cuál es el futuro que se desea, pero además, mirar el pasado para tratar de explicar el hoy, sus vicisitudes y propuestas transformadoras. Pero este efecto de la educación para la paz no se genera por sí solo si no existe:

- Esperanza: creer que la transformación es posible.

- Amor: indispensable para pensar en la humanidad.

- Compromiso: no ser indiferente ante la injusticia, asumir que hay algo que hacer.

- Sueño: visualizar la posibilidad de avanzar, de un mundo diferente.

- Educación para convivir: para una convivencia con significado, con dignidad y pacífica.

- Educación para la solidaridad: educar para compartir, para ayudar, para cooperar, para comprometerse con la humanidad.

- Educar para comprendernos: implica respeto, aceptación, aprecio, alteridad, empatía.

- Educar para el diálogo: es un medio y un fin, para solucionar conflictos, para hacer propuestas, para reflexionar y criticar las realidades. 


\section{Referencias}

Briggs, J. y Peat, D. (1999). Las siete leyes del caos. Las ventajas de una vida caótica. Barcelona: Grijalbo.

Caireta, M. y Barbeiro, C. (2005). "Introducción de conceptos: Paz, violencia, conflicto". Cuadernos de educación para la paz. Barcelona: Escola de cultura de pau (ECP). Recuperado de http:// escolapau.uab.cat/index.php?option=com content\&view=article\&id=62\&ltemid=92\&lan $\mathrm{g}=\mathrm{es}$

Cazau, P. (1995). La teoría del caos. Recuperado de www.antroposmoderno.com/antro-articulo. php?id articulo $=152$

Declaración de Luarca (Asturias) sobre el derecho humano a la paz. (2008). Revista de paz y conflictos, 1, 109-119. Recuperado de http://www.ugr.es/ revpaz/numeros/numeros. html\#numero1

Gómez, M. E. (2010). “La Educación para la paz aplicada a la tutoría académica en la Facultad de Ciencias Políticas y Sociales de la Universidad Autónoma del Estado de México". Revista Paz y Conflictos, 3, 2010, 123-139. Recuperado de http://www.ugr.es/ revpaz/tesinas/ rpc n3 2010 dea3.pdf

Jares, X. (1999). Educación para la paz. Su teoría y su práctica (2ª ed.). Madrid: Popular.

Jares, X. (2004). Educar para la paz en tiempos difíciles. Bilbao: Bakeaz. Recuperado de http://ficheros. bakeaz.org/SG14 completo.pdf

Lorenz, E. N. (2001). The essence of chaos [La esencia del caos] (4 ed.). (Apéndice 1, pp. 181-184). Seattle: University of Washington Press.

Monclús, A., Sabán, C. (1999). Educación para la paz. Madrid: Editorial Síntesis.

Naciones Unidas. (1999). Resoluciones 53/243 de 6 de octubre de 1999. Declaración y programa de acción sobre una cultura de paz. Recuperado de http://www.unesco.org/cpp/sp/proyectos/ suncofp.pdf

Naciones Unidas (s. f.). Declaración Universal de Derechos Humanos. Recuperada de http://www. un.org/es/documents/udhr/

Real Academia Española (RAE). (2001). Diccionario de la Real Academia Española. Vigésima segunda edición. Recuperado de http://buscon.rae.es/drael/SrvltConsulta?TIPO BUS=3\&LEMA=Hacer

Restrepo, M. (2011). Educación en derechos humanos y paz: La experiencia colombiana. En UNESCO. IV Jornadas de Cooperación Iberoamericana sobre Educación para la Paz, la 


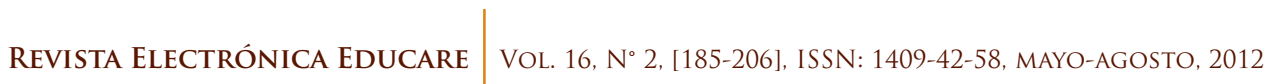

URL: http://www.una.ac.cr/educare

Convivencia Democrática y los Derechos Humanos (pp. 189-200). Santiago, Chile: OREALC/ UNESCO. Recuperado de http://unesdoc.unesco.org/images/0019/001916/191613s.pdf

Torres, C. (2007). Conceptualización y caracterización de la educación no formal. En C. Torres y Pareja, J. A. (Coords.). La educación no formal y diferenciada: Fundamentos didácticos y organizativos (pp. 11-38). España: CCS. 